\title{
A Psicologia no Contexto das Comunidades Tradicionais: da Emergência Étnica à Perspectiva Ético-Estético-Política
}

\author{
Antonio Vladimir Félix-Silva ${ }^{1}$ \\ ${ }^{1}$ Universidade Federal do Piauí, PI, Brasil. \\ Ana Caroline Santos ${ }^{3}$ \\ ${ }^{3}$ Universidade Potiguar, RN, Brasil.
}

\author{
Gabriela Pinheiro Soares ${ }^{2}$ \\ ${ }^{2}$ Fundação Gregório Baremblitt, MG, Brasil. \\ Lara Mendes Braga Rigoti ${ }^{4}$ \\ ${ }^{4}$ Universidade Federal do Rio Grande do Norte, RN, Brasil.
}

Maria Valquiria Nogueira Nascimento ${ }^{5}$

${ }^{5}$ Universidade Federal de Campina Grande, PB, Brasil.

\begin{abstract}
Resumo: Neste artigo, apresentamos um estudo sobre produção de subjetividade de mulheres da Comunidade Quilombola de Macambira e produção de subjetividade de psicólogas pesquisadoras, durante uma pesquisa de trabalho de conclusão de curso. Trata-se de uma pesquisa-intervenção para compreender como se dá a produção dos modos de viver da mulher quilombola, objetivando cartografar seus processos de subjetivação e analisar os processos de subjetivação das psicólogas pesquisadoras no encontro com as mulheres participantes da pesquisa. Para a produção das informações usamos o método cartográfico, com visitas às casas das mulheres e à comunidade e realizamos oito encontros com oito mulheres por meio de práticas integrativas grupais. A análise das observações e narrativas registradas em diário cartográfico deu-se por meio dos analisadores que emergiram dos processos de subjetivação cartografados. A discussão e resultados mostram que a produção da subjetividade das psicólogas e da identidade mulher quilombola bem como da emergência étnica Comunidade Remanescente de Quilombo constituem uma construção social, dentro de um sistema histórico-cultural complexo. A análise dos processos de subjetivação que emergem do encontro das psicólogas pesquisadoras com as mulheres quilombolas aponta para a (des)construção de identidades segmentadas, possibilitando a ressignificação da relação entre pesquisador e participante da pesquisa, efeito da cartografia como modo de fazer pesquisa-intervenção. A produção de subjetividade das mulheres quilombolas está marcada pela sororidade e interseccionalidade, singularizações e reproduções de relações de saber e poder vigentes, que também atravessam os processos de subjetivação das psicólogas pesquisadoras.
\end{abstract}

Palavras-chave: Comunidades Tradicionais, Mulheres Quilombolas, Cartografia, Formação em Psicologia, Processos de Subjetivação. 


\title{
Psychology in the Context of Traditional Communities: From the Ethnic Emergence to the Ethical-Esthetic-Political Perspective
}

\begin{abstract}
This article aims to understand the subjectivity of women in the Quilombola Community of Macambira and the production of subjectivity of research psychologists during a monograph survey. This is an intervention research to understand how the quilombola woman lives, aiming to map and analyze the processes of subjectivation of the research psychologists in the encounter with the women participating in the research. For the production of information, we used the cartographic method, with visits to women's houses and the community. In addition, we also held eight meetings with eight women through group complementary and integrative practices. The analysis of the observations and narratives recorded in the cartographic diary happened because of the analyzers that emerged from the mapping of the subjectivity of the participants. The discussion and results show that the production of research psychologists and quilombola woman identity and the ethnic emergence of the remaining quilombo community constitute a social construction, within a complex historical-cultural system. The analysis of the subjectivities that emerge from the meeting of research psychologists with quilombola women points to the (de) construction of segmented identities, making possible the re-signification of the relation between researcher and participant of the research, an effect of cartography as a way of doing intervention research. The subjectivity of quilombola women is marked by sorority and intersectionality, singularities and reproductions of current knowledge and power relations, which are also present in the subjectivities of research psychologists.
\end{abstract}

Keywords: Traditional Communities, Quilombola Women, Cartography, Training in Psychology, Subjectivity. 


\title{
La Psicología en el Contexto de las Comunidades Tradicionales: de la Emergencia Étnica a la Perspectiva Ético-Estético-Política
}

\begin{abstract}
Resumen: En este artículo, presentamos un estudio sobre producción de subjetividad de mujeres de la Comunidad Quilombola de Macambira y producción de subjetividad de psicólogas investigadoras, durante una investigación de trabajo de conclusión de curso. Se trata de una investigación-intervención para comprender cómo se da la producción de los modos de vivir de la mujer quilombola, objetivando cartografiar sus procesos de subjetivación y analizar los procesos de subjetivación de las psicólogas investigadoras en el encuentro con las mujeres participantes de la investigación. Para la producción de las informaciones usamos el método cartográfico, con visitas a las casas de las mujeres ya la comunidad y realizamos ocho encuentros con ocho mujeres por medio de prácticas integradoras grupales. El análisis de las observaciones y narrativas registradas en diario cartográfico se dio a través de los analizadores que surgieron de los procesos de subjetivación cartografiados. La discusión y resultados muestran que la producción de la subjetividad de las psicólogas y de la identidad mujer quilombola así como de la emergencia étnica Comunidad Remanente de Quilombo constituyen una construcción social dentro de un sistema histórico-cultural complejo. El análisis de los procesos de subjetivación que emergen del encuentro de las psicólogas investigadoras con las mujeres quilombolas apunta a la (des) construcción de identidades segmentadas, posibilitando la resignificación de la relación entre investigador y participante de la investigación, efecto de la cartografía como modo de hacer investigación-intervención. La producción de subjetividad de las mujeres quilombolas está marcada por la sororidad e interseccionalidad, singularizaciones y reproducciones de relaciones de saber y poder vigentes, que también atraviesan los procesos de subjetivación de las psicólogas investigadoras.
\end{abstract}

Palabras clave: Comunidades Tradicionales, Mujeres Quilombolas, Cartografía, Formación en Psicología, Procesos de Subjetivación.

\section{Carta-introdução}

A história da diáspora negra no Brasil é marcada pelo tráfico de quatro milhões e novecentos mil homens e mulheres trazidos da África (Schwarcz, \& Starling, 2015) para exploração comercial na condição de trabalho em regime de escravidão, consolidando a genealogia do racismo institucional no Estado Colonial, cuja implementação se deu, inicialmente, sobre os povos indígenas. Esta condição incluía práticas de tortura, surras e castigos praticados pela raça branca contra o corpo negro. Sem dúvida, essa história também é marcada por momentos de insurreição do corpo (Rolnik, 2018), sendo o mais conhecido o movimento que gerou a formação dos Quilombos, com destaque para as lideranças Zumbi dos Palmares e Dandara. Trezentos anos de escravização e contra este sistema, a resistência que durou, praticamente, cem anos, caracterizando a luta pela emancipação em pequenas comunidades rurais. "No séculoXVII, o Qui- lombo dos Palmares já se erigia como uma espécie de república negra de contraposição à força escravocrata oficial [...], seus habitantes desenvolveram um Estado à margem com arcabouço político, econômico, social e cultural próprios" (Santos, 2016, pp. 67-68). Mais de um século depois da abolição da escravização, a população pobre, composta, em sua maioria, pelo povo negro, vivia (e ainda vive) sob o jugo da violência, da exclusão social e do racismo. Entre o romantismo em torno da miscigenação das raças e a negação do racismo, surge, nas décadas de 1950 e 1960, a questão da emergência étnica, com os estudos culturais, entre os anos 1980 e 1990, apontando para a diversidade e a necessidade de reconhecimento das especificidades de grupos étnico-culturais, cuja luta por dignidade e diretos ganha visibilidade a partir da década de 1990 (Arruti, 1997; Silva, 2009).

Durante as fases colonial e imperial, os Quilombos eram vistos como "organizações criminosas" cujos 
membros sofriam restrições e punições. Mesmo com sua histórica luta e movimento de resistência, eles seguiram marginalizados e ausentes do campo jurídico republicano; de tal modo que quilombo somente se tornou reconhecido "enquanto categoria social e política, pertencente à formação nacional brasileira, pela Constituição Federal de 1988" (Marques, 2018, p. 136) que em seus Artigos 215 e 216 garante os direitos culturais, materiais e simbólicos das comunidades indígenas e afro-brasileiras. Assim, o território vivo (Santos, \& Silveira, 2010), tradicionalmente ocupado por comunidades negras, "exprime um direito a ser reconhecido na vida cotidiana dos quilombolas" e a categoria "remanescentes de comunidades de quilombos" ou "remanescente de quilombo" constitui uma identidade pertencente a "uma comunidade e enquanto tal trata-se de uma unidade viva, um locus de produção material e simbólica", cujo "processo de afirmação quilombola não passa pelo resíduo, pela sobra ou 'pelo que foi e não é mais', senão pelo que de fato é, pelo que efetivamente é vivido" (Marques, 2018, p. 135).

A Fundação Cultural Palmares, órgão do governo federal cuja fundação foi autorizada em 1988 e, a materialização se deu em 1992, no governo Itamar Franco, tinha como objetivo identificar e propor por meio de laudo antropológico o tombamento de sítios e populações remanescentes de quilombos. Não obstante, até os primeiros anos do governo Fernando Henrique Cardoso, 1994/1997, no que se refere à regularização do território, houve pouco avanço, e, mesmo reconhecendo como um direito, na segunda gestão, as medidas adotadas pela política de titulação de territórios quilombolas não foram suficientes, haja vista que o Decreto ${ }^{\circ} 3.912 / 2001$, que regulamentava o Artigo 68 do ato das Disposições Constitucionais Transitórias (ADTC) partia de uma preconcepção de quilombo, na qual ignorava a dinâmica sócio-histórica dos grupos sociais e não considerava a questão da autoidentificação da comunidade quilombola como sujeito de direto, tal como preconiza a Convenção 169 da Organização Internacional do Trabalho acerca dos povos e comunidades tradicionais e autóctones; autoidentificação como critério para o reconhecimento da comunidade como sujeito de direito, somente reconhecida a partir do governo Luís Inácio Lula da Silva (2003/2010), por meio da implementação, pela primeira vez, de uma política de regulamentação territorial quilombola (Marques, 2018); período no qual, um de nós participou e acompanhou o trabalho de antropólogos com essa finalidade, junto à Associação das Comunidades Negras Rurais Quilombolas do Maranhão (ACONERUQ).

Neste contexto, Santos, Schucman e Martins, (2012) afirmam que a Psicologia tem três momentos de interface com as relações étnico-raciais no Brasil:

a) Período do final do século XIX e início do XX - caracterizado pelo surgimento e consolidação de um modelo médico-psicológico [...]; (b) Período de 1930 até 1950 - caracterizado pela [...] crítica e de desconstrução do determinismo biológico das raças na constituição do campo da Psicologia e da Psicologia social no Brasil; (c) Período de 1990 em diante - caracterizado [pelos] [...] debates e ações de promoção da igualdade étnico-racial no Brasil. [...] [E os] efeitos psicológicos sobre a identidade étnico/racial da pessoa negra [...]. (pp. 167-168).

Para além da questão e importância da emergência étnica, apostamos na perspectiva ético-estético-política como dispositivo de problematização de identidades segmentadas (Rolnik, 2000) e como modo de contribuir para a superação dos conflitos entre grupos étnicos emergentes em torno das políticas púbicas e dos programas sociais. Tal perspectiva, no presente estudo, também nos possibilita fazer a problematização de outras identidades segmentadas, aqui, no âmbito da formação em Psicologia.

Nos contextos da sociedade de controle, todas e todos nós trabalhamos com produção de subjetividade (Guattari, \& Rolnik, 2010). Nessa perspectiva, durante mais de dez anos de trabalho com técnicas de intervenção em grupo, nosso maior desfio tem sido mostrar que seu uso pode superar os modos de subjetivação segmentados em uma técnica reificada, haja vista que durante a formação de psicólogas(os), "somos segmentarizados por todos os lados e em todas as direções" (Deleuze; \& Guattari, 2012, p. 92). Esse agenciamento dos processos de subjetivação pode produzir como efeito a reprodução de técnicas psi que não contribuam com a produção de novas subjetividades mais sensíveis às injustiças sociais e acabem fazendo, inclusive durante a pesquisa-intervenção, uma redução epistemológica do devir grupo sujeito dos participantes a um grupo modo-indivíduo (Barros, 2013) e preconcebendo comunidade qui- 
lombola à "noção de segmentariedade [...] construída por etnólogos para dar conta das sociedades primitivas, sem aparelho de Estado central físico, sem poder global nem instituições políticas [...] com um domínio de base (econômico, político, jurídico, artístico)", etc. (Deleuze, \& Guattari, 2012, p. 93). Pelo contrário, desejamos que as técnicas de intervenção em grupo, seja no campo da Psicologia Social Comunitária, das psicoterapias e terapia de grupo seja no campo da pesquisa-intervenção, possam contribuir com a produção de uma sociedade mais solidaria. "Não a de "irmãos", fundada em compactas identidades, no medo e na culpa que assassinou índios, negros e os que transgrediram a Ordem dos corpos e dos afetos, mas uma solidariedade gerada pelas interpelações do diverso e da indignação" (Baptista, 1999, p. 30).

Diante do exposto, neste estudo, apresentamos um relato de pesquisa a partir de uma cartografia dos processos de subjetivação de mulheres de uma Comunidade Quilombola, recorte de uma pesquisa-intervenção sobre o uso da Terapia Comunitária como Estratégia de Intervenção na Atenção Básica em Saúde ${ }^{1}$. Não obstante, não iremos explorar a questão do uso da terapia comunitária nem das técnicas de intervenção em grupo, haja vista que esta não era demanda implícita nem explícita das mulheres da comunidade. O foco indagatório, deste estudo, está relacionado aos processos de subjetivação das mulheres da comunidade e à análise dos processos de subjetivação que emergiram do encontro das psicólogas pesquisadoras com as mulheres, participantes da pesquisa, ou seja, à cartografia dos processos de subjetivação que se configuraram no modo de fazer pesquisa-intervenção nos contextos de uma comunidade remanescente de quilombo.

A experimentação do encontro entre psicólogas-pesquisadoras, aprendentes da cartografia, e as mulheres da comunidade quilombola gerou uma problematização: Como se configuram os processos de subjetivação de psicólogas(os) diante da necessidade de escrever um trabalho de conclusão de curso a partir da (des)construção de um olhar centrado em uma técnica de intervenção em grupo? Nesta perspectiva, objetivamos cartografar processos de subjetivação das mulheres quilombolas e analisar os processos de subjetivação das psicólogas, escolhendo a cartografia como modo de fazer pesquisa-interven- ção e a escrita cartográfica no estilo de cartas-intervenção. Trata-se de

um modo de fazer, de operar, de agir com a escrita e com o pensamento capaz de propor tensionamentos, desvios e aberturas, principalmente, porque se propõe problematizar as relações, que, historicamente, construímos como a verdade e com os seus desdobramentos, inoculando nelas a experimentação de composições outras (precárias, permeadas por interrupções e descontinuidades) (Cordeiro, 2016, p. 4).

Por meio do acompanhando dos processos de subjetivação das mulheres, participantes da pesquisa, e das psicólogas-pesquisadoras, mapeamos fluxos que foram se intensificando na medida em que adentramos esse território afetivo-existencial, denominado Comunidade de Remanescentes de Quilombo. Cartografia e cartas-intervenção para "expandir-se em surpresas, em molecagens que escrevem e rasuram inúmeras versões de nós mesmos [mesmas]. É artefato que corrompe as formas prontas" (Preciosa, 2010, p. 67).

A primeira carta-intervenção que a pesquisa apontou, durante o processo, está relacionada à rasura do pré-projeto de trabalho de conclusão de curso das psicólogas para compor nosso projeto guarda-chuva e à desconstrução dos objetivos traçados $a$ priori: a) Investigar a produção de subjetividade em mães quilombolas; b) Caracterizar os processos de subjetivação em um grupo de mães da Comunidade Quilombola de Macambira utilizando a terapia comunitária; c) Identificar os modos de viver e existir no cotidiano das mães de uma Comunidade Quilombola; d) Analisar os processos de subjetivação e produção de subjetividade em mulheres-mães da Comunidade Quilombola de Macambira.

À medida que o campo de intervenção foi se misturando com o campo de análise, o olhar das psicólogas foi se deslocando da figura da mãe quilombola, mulher-mãe, identidade segmenta pelo olhar do pesquisador estrangeiro, e da oração para "amolecer o coração" de outra comunidade quilombola que não permitia a entrada de voluntários de uma organização não governamental (ONG) evangélica, da qual um de nós fazia parte. As psicólogas pesquisadoras foram se

${ }^{1}$ Protocolo aprovado pelo Comitê de ética em Pesquisa, conforme número de CAAE 0112.0.052.000-09. 
aproximando mais da produção de subjetividade das mulheres e de sua multiplicidade de devires, podendo, em alguns momentos, devir quilombola no sentido de experimentação dessa produção de subjetividade, sem necessariamente identificar-se com uma identidade étnica como segmentariedade (Deleuze, \& Guattari, 2012). Pouco a pouco, nossa análise, durante as orientações e acompanhamento da pesquisa, foi mostrando a coexistência de modos de subjetivação marcados não só por atravessamentos da instituição família e religião, instituições cujos efeitos vão ocupando, inicialmente, os lugares das tendências instintivas (Deleuze, 2006), mas também pelas representações que atravessam o imaginário social sobre uma comunidade tradicional e denunciando a ausência de discussão mais aprofundada por docentes e discentes a partir de currículos e projetos pedagógicos dos cursos de Psicologia, como parte das Referências Técnicas para atuação de psicólogas/os. De tal modo que a Psicologia como dispositivo de produção de subjetividades acaba, de certa forma, corroborando com o racismo institucional, ou seja, com essa "ideologia de abrangência ampla, complexa, sistêmica, violenta, que penetra e participa da cultura, da política, da economia, da ética,..., enfim, da vida subjetiva, vincular, social e institucional das pessoas" (CFP, 2017, p. 10). Neste cenário de práticas, pensamos que este relato de pesquisa possa contribuir com os diferentes modos de existência no campo da diversidade étnico-racial e corroborar com o debate em torno da formação em Psicologia e dos "diferentes projetos ético-políticos simultaneamente propostos que disputam a hegemonia da profissão" (Yamamoto, 2012).

\section{Carta-método}

Diante dessa problemática, optamos pela realização de uma investigação qualitativa com o uso do método cartográfico e de estratégias metodológicas participativas para a produção das informações. Além das reuniões semanais com as psicólogas-pesquisadoras, aspirantes a cartógrafas, e das visitas à comunidade e às casas das participantes da pesquisa em Macambira, realizamos oito encontros com oito mulheres. Os encontros foram mediados por rodas de conversa, tenda do conto e círculos de cultura com artefatos da arte como desenho, bordado e mostra de um curta-metragem. As observações e narrativas foram registradas em Diário Cartográfico (EPS em Movimento, 2014). Partimos da esquizoanálise e de suas ferramentas conceitos e concepção de produção de subjetividade capitalística (Guattari, \& Rolnik, 2010) para análise dos processos de subjetivação com suas segmentariedades e singularizações; assim, seguimos algumas notas propostas por Rolnik (2018) sobre "ressonâncias dos afetos das forças do presente" (p. 27), ora para a reprodução, ora para a superação dos "aspectos medulares do modo de subjetivação do inconsciente colonial-capitalístico" (p. 52).

As psicólogas chegaram ao campo de pesquisa na expectativa de que em algum momento poderia emergir a necessidade de constituir uma vivência de terapia comunitária com as mulheres, mesmo que já tivéssemos assinalado para iniciar com uma roda de conversa e ouvir as narrativas da comunidade. A demanda implícita das aprendentes de cartógrafas ainda estava segmentada numa técnica de intervenção e seus modos de subjetivação centrados na figura da mulher-mãe, e não necessariamente da mulher quilombola, "uma espécie de reciclagem ou de formação permanente para volta a ser mulher ou mãe", efeitos da máquina de produção de subjetividades capitalísticas que operam na lógica da naturalização e da institucionalização dos corpos e da economia coletiva do desejo (Guattari, \& Rolnik, 2010, p. 33). Não obstante, as mulheres quilombolas estavam atentas às experiências de vida, e ao papel do Estado frente às demandas na esfera de políticas públicas haja vista o campo de disputas marcado pelos discursos vigentes sobre relações étnico-raciais e pela correlação de forças que prevalecia no contexto, ora de afirmação, ora de negação dos "novos direitos advindos da identificação quilombola” (Mello, 2009, p. 587).

A rasura da primeira carta-intervenção (terapia comunitária) e a mudança dos objetivos preestabelecidos deixam as psicólogas gaguejando, "desajeitadas” (porque sem jeito, sem forma, sem padrão preestabelecido). Sem dúvida, com esse desassossego, nos abrimos para a possibilidade de tensionar a corda das palavras que buscávamos enquanto escrevíamos outra carta-intervenção a partir das afetações com os primeiros encontros que nos levaram a nos reconhecer no modo de fazer pesquisa escolhido. Este que nos permite tatear, seguindo pistas, algumas vezes malogrando, vale dizer, porém sempre cultivando uma disponibilidade às experiências. Então, passamos a devir brincante, explorando e nos movendo pela "plena positividade de um desejo criador, que se manifesta em um eterno e incessante jogo de construção e des- 
truição" (Ferraz, 2002, p. 34). Acionamos a potência intensiva de inventar novos mundos (ou outras formas de enxergar o mundo) através de uma ética e uma estética do pensamento. É o pensamento que impulsiona estas outras formas de enxergar as coisas ao redor: o pesquisador, os sujeitos da pesquisa e as práticas em Psicologia.

A pesquisa foi realizada na Comunidade Quilombola Macambira III, que está situada na Serra de Santana nos municípios de Lagoa Nova, Bodó e Santana dos Matos, fronteira entre os sertões do Seridó e Vale do Açu, no Estado do Rio Grande do Norte. A cartografia, como modo de fazer pesquisa-intervenção e as práticas integrativas grupais como estratégias de produção de dados, informações e narrativas nos mostraram que outros analisadores foram surgindo a partir das visitas iniciais, diante dos encontros com a comunidade. À flor da pele, a beleza do caminho até Macambira, as serras que se avistam ao longe, o verde lutando pela sobrevivência em solo seco. Macambira que, em pleno sertão, conserva uma brisa suave, um ar puro e um resto de frio vindo da serra.

As aspirantes a cartógrafas começam a se sentir bem naquele lugar tranquilo, que é diferente do lugar de onde elas vêm e onde moramos, cidade cheia de verticalidade, poluição sonora, rapidez e concreto. Elas conheceram Úmaro ${ }^{2}$, líder da comunidade, e apresentam nossa proposta de trabalho, que consiste em realizar uma pesquisa-intervenção com mulheres da comunidade, a partir da realização de rodas de conversa, tenda do conto e terapia comunitária. Visitam as casas de algumas mulheres e as convida para que participem da pesquisa. Dez mulheres aceitam participar ${ }^{3}$. Elas se sentem acolhidas, ao mesmo tempo, o medo da hospitalidade das participantes dá lugar a um estranhamento por parte delas em relação à proposta de trabalho. Afinal, elas se apresentam como estudante de Psicologia e se perguntam qual o papel que se espera em uma pesquisa-intervenção para um trabalho de conclusão de curso? O que se espera da prática de um psicólogo? Registramos no nosso diário cartográfico (EPS em Movimento, 2014) o fato de ser um homem o líder da comunidade, sabendo que esse atravessamento de gênero faz dizer e falar sobre aquele território existencial.
A história da comunidade de Macambira começa com a formação da Comunidade Quilombola, muito antes do nascimento de Lázaro, um dos filhos de descendentes africanos, e das histórias de seu Adulai, bisneto de Lázaro. Seu Adulai conta como seus antepassados lutaram pelas terras de Macambira, do "sofrimento que sempre foi essa vida". Falar da Comunidade de Remanescentes Quilombolas de Macambira é falar de como seu povo chegou àquelas terras, das suas lutas no Continente Africano, da escravidão no Brasil. É falar de sofrimento, de conquistas e de movimentos de resistência. Um caminho longo pelo qual homens e mulheres passaram para que, hoje, o povo de Macambira tenha o direito à terra reconhecido, muito embora a luta por direitos políticos e sociais nunca tenha cessado.

De acordo com o relatório "Comunidade de Macambira: de negros da Macambira à associação quilombola" (Pereira, 2007), desde o século XIX a formação sócio-histórica dessa comunidade vinha sendo construída como remanescentes de comunidade quilombolas que surgiu a partir da reunião de famílias negras nas terras compradas por Lázaro Pereira de Araújo, um ex-escravo que se tornou dono de uma grande área, onde foram criadas as famílias e laços de casamento e compadrio, que, com o passar dos anos, foi se ampliando as redes de matrimônio, passando a acontecer também com os colonos pobres. Mas, foi somente em 29 de julho de 2005 que a comunidade obteve a certidão de autorreconhecimento como remanescente quilombolas através da Fundação Cultural Palmares, Ministério da Cultura e Diretoria de Proteção ao Patrimônio Afro-Brasileiro, a partir do processo de delimitação e demarcação das terras ocupadas e dos analisadores "nominação, identificação, reconhecimento e territorialização" que constituem dispositivos do agenciamento do processo de produção de subjetividade em uma comunidade tradicional com seus fluxos sinuosos, contínuos e descontínuos e com suas linhas de fuga e jogos de captura (Arruti, 2006).

Para Schmitt, Turatti e Carvalho (2002), as comunidades hoje consideradas remanescentes de quilombos formaram-se a partir de diversas formas de agrupamento, que incluem fugas com ocupação de

${ }^{2}$ Para preservar o sigilo dos integrantes desta pesquisa, seus nomes foram substituídos por nomes de origem africana.

${ }^{3}$ A participação das mulheres sofreu variação entre e 8 e 9, sendo um dia, com 10, haja vista a participação e dois homens. 
terras livres, heranças, doações e recebimento de terras como pagamento de serviços prestados ao Estado. Atualmente, o que configura uma comunidade como remanescentes de quilombos ou como uma comunidade quilombola é a pertença do grupo à terra, o sentimento de identidade e de territorialidade que marcam o processo de territorialização.

Quando compomos a paisagem psicossocial da Comunidade Quilombola de Macambira e mapeamos suas peculiaridades, sua forma de pertença, sua forma de relacionar-se, emergiu como analisador a fluidez do conceito de identidade quilombola. Nesta comunidade, também se aplica a assertiva de Deleuze e Guattari (2015): "nada de agenciamento maquínico que não seja agenciamento social do desejo, nada de agenciamento social de desejo que não seja agenciamento coletivo de enunciação" (p. 149). Neste sentido, assinalamos, anteriormente, os analisadores que constituem a produção de subjetividade e seu agenciamento em comunidades remanescentes de quilombos e a coexistência de processos de subjetivação que apontam na perspectiva do devir comum minoritário (Guattari, 1981), noção a partir da qual Deleuze e Guattari (2012) pensaram o analisador minorias no plural para relacioná-lo ao devir minoritário e à minoria como "conjunto plural de capacidades produtivas, de capacidades de cooperação, de desejos" (Negri, 2001, p. 32) efeito de um agenciamento coletivo do desejo de mundo em uma comunidade por vir, a qual Negri e Guattari (2017) nomeiam de comunismo. Negri (2001) afirma "o comunismo é a multidão que se torna comum” (p. 32).

\section{Carta-resultados e discussão}

As psicólogas se frustraram, inicialmente, quando perceberam que não existia demanda para terapia comunitária, estavam desejosas de pôr em prática os conceitos de acolhimento, de escuta e de cuidado que tanto ouviram falar na Academia. Também se frustraram quando não encontraram naquela comunidade um aparato cultural digno do que os desavisados consideram ser o esperado de uma comunidade quilombola. Perderem-se e nos perdemos das rotas traçadas no mapa antes da primeira ida a campo. Foi preciso criar outras estratégias. "Toda pesquisa nasce de um desejo: por detrás do sujeito da pesquisa está o sujeito pesquisador com seus sonhos, entraves e buscas..." (Mello, 1999, p. 19).
Então, retomamos os fios de errância que contornam a cartografia como modo de fazer pesquisa-intervenção e passamos a atentar para a implicação em relação à pesquisa. Implicação esta que fala sobre os desejos que movem o pesquisador, desejos estes que muitas vezes o pesquisador pode confundir como a própria demanda do campo de pesquisa. Compreendemos que pesquisar cartograficamente é isso: é perguntar sobre implicação, sobre desejo, sobre os sentimentos que perpassam o pesquisador no campo de pesquisa. Como aprendentes de cartógrafas as pesquisadoras se frustraram, inicialmente; no lugar de experimentação, como orienta a perspectiva ético-estético-política, intepretação: pensaram que as mulheres daquela comunidade não se abriram suficientemente para mostrar suas vulnerabilidades, para que, assim, pudessem seguir com a 'meta' de Terapia Comunitária. Não sabiam que as vulnerabilidades eram mais da Psicologia e nossas. "A prática da investigação não pode ser determinada só pelo interesse do pesquisador, devendo considerar também o protagonismo do objeto. A investigação é cuidado ou cultivo de um território existencial no qual o pesquisador e o pesquisado se encontram (Alvarez, \& Passos, 2010, p. 144).

A partir da análise e da carta-intervenção nos processos de subjetivação das psicólogas-pesquisadoras, fomos mapeando outros sentidos para o modo de fazer pesquisa-intervenção para além do uso de uma técnica de intervenção. Pesquisar é falar de encontros, não aqueles forjados, planejados, mas aqueles que ocorrem às cegas, onde a surpresa e a imprevisibilidade são os únicos guias. Ao analisar o trabalho de pesquisa cartográfica, Kastrup (2008) apresenta quatro modos de atenção que constituem esse trabalho: "o rastreio, o toque, o pouso e o reconhecimento atento" (p. 40). Pensamos que pesquisar diz muito mais desse pouso ou repouso do que de movimento; não um repouso passivo, todavia um repouso que se faça a partir da observação, da abertura, da disponibilidade aos acontecimentos.

Foi observando acontecimentos que as pesquisadoras-cartógrafas e nós com o pensamento deambulando, deixamos nossa escuta nos guiar outra vez pelas vozes que nos respondem, reclamando por políticas públicas de saúde eficazes. Vozes da Comunidade Quilombola que denunciam um serviço de saúde distante, literalmente distante, dez quilômetros a serem percorridos até chegar à 
Unidade Básica de Saúde mais próxima de Macambira. Então, recorremos à concepção de dor, dor mediada pelas injustiças sociais; tal qual o banzo, essa dor mata, por ela morre-se ou se entope de psicotrópico: o sofrimento ético-político. Ele "retrata a vivência cotidiana das questões sociais dominantes em cada época histórica, especialmente a dor que surge da situação social de ser tratado como inferior, subalterno, sem valor, apêndice inútil da sociedade" (Sawaia, 2008, p. 104).

Trata-se de produção de subjetividade capitalística e de um capitalismo global, marcados pela necrobiopolítica. São outros e são os mesmos os navios negreiros atuais (territórios de existência), em que a população quilombola é esquecida ou jogada, é matada, é morrida por um pedaço de terra seu, por um pedaço de corpo seu, por uma vida que vale menos do que outras e por isso também esquecida nos porões escuros das comunidades quilombolas (territórios longínquos, não só geograficamente, mas longe também da chegada das políticas de assistência social e da presença de profissionais da saúde). Escrevemos porões escuros, mas não se trata apenas de uma metáfora, pois esta era a realidade da Comunidade Remanescente de Quilombolas de Macambira há pouco menos de dez anos - a energia elétrica só chegou recentemente à comunidade por meio do programa Luz para Todos. Esta análise dos processos de subjetivação parte do que os membros da Comunidade Quilombola de Macambira nos fez ver e falar e nos faz escrever: "Tudo aqui se começa e nada se termina, época de política todo dia tem reunião, mas o povo aqui é 'amundiçado', não sabe falar e quando tem reunião com o povo educado eles [o povo] se enjoam logo e vão embora" (Dona Fatumatá); "Ninguém acredita mais nessas promessas de casa e banheiro" (Salí); "Se for preciso eu me humilho para o prefeito"(Lánica); "Pois eu prefiro morrer aqui estirada, não me humilho, não peço nada, tenho trauma de hospital, já fui muito humilhada" (Diuni).

Quando habitamos este território existencial, estávamos atentos a estas pequenas sutilezas: práticas discursivas que denunciava a falta de políticas públicas e a descredibilidade com a política, e anunciavam também processos de subjetivação segmentados por uma retórica histórica sobre outros navios negreiros - os navios da desvalorização do conhecimento da comunidade e da deslegitimidade social. Quando dona Fatumá nomeia os moradores de "amundiçados" e os políticos de "povo educado", seus processos de subjetivação estão nos fazendo analisar todo um discurso que é produzido e reproduzido enquanto lugar verticalizado de fala. "Grada Kilomba [...] faz uma analogia interessante entre a máscara que as pessoas escravizadas eram obrigadas a usar cobrindo a boca e a afirmação do projeto colonial de impor silêncio visto como a negação de humanidade e de possibilidade de existir como sujeito" (Ribeiro, 2018, p. 18).

Contra esse Ethos do Silêncio, Ribeiro (2018) reivindica o lugar de fala das mulheres negras. Não deveríamos nos calar por estas nem por outras relações de saber, poder e regime de verdades que marcam a produção de subjetividade vigente, relações estas que atribuem ao povo à indignidade do falar - porque não sabe, porque não tem conhecimento, porque não se entende. São as dobras do regime colonial-capitalístico (Rolnik, 2018) que também pode produzir e produz como efeito, o sofrimento ético-político, aquele que "abrange as múltiplas afecções do corpo e da alma que mutilam a vida de diferentes formas. Qualifica-se pela maneira como sou tratada e trato o outro na intersubjetividade, face a face ou anônima, cuja dinâmica, conteúdo e qualidade são determinados pela organização social" (Sawaia, 2008, p. 104).

Na sombra das horas, o grito de liberdade, o lugar de fala e a felicidade pública, ou seja, a potência de ação gerada pela sensação de "vitória como conquista da cidadania e da emancipação de si e do outro" (Sawaia, 2008). "Da calma e do silêncio", poema de Evaristo (2008, p. 70), nos remete à felicidade ético-política. Os primeiros versos dizem: "Quando eu morder A palavra, Por favor, Não me apressem, Quero mascar, Rasgar entre os dentes, A pele, os ossos, o tutano Do verbo Para assim versejar No âmago das coisas".

Para habitar um território existencial é preciso desaprender o silêncio e morder a palavra. Nos primeiros encontros com as mulheres da comunidade de Macambira, as psicólogas procuraram elementos que singularizassem a cultura daquele povo - a ideia de um reduto de quilombo - uma ideia de pesquisadores brancos? Elas se perguntam e nos perguntamos, de algum modo, pela tradição e esperam que as mulheres da comunidade mostrem algo como: instrumentos musicais como os tambores, a cuíca, o berimbau; danças tradicionais como os congados, maculelê, maracatu, coco etc.; religiões afro-brasileiras como o candomblé e a umbanda. 
A sensação das mulheres era de estranhamento. Pouco a pouco, fomos nos dando conta que para aquela comunidade, como para outras tantas, a implementação de programas sociais, a exemplo de Luz para Todos e Minha Casa, minha Vida, depende do reconhecimento de uma identidade jurídico-política, de modo que, para que uma comunidade possa ter acesso a essas e outras políticas públicas precisa buscar a afirmação de sua identidade étnico-cultural como quilombola, por exemplo, embora, um ou outro integrante, até então, não se reconhecesse como tal.

Estamos diante de um analisador que nos abre outras formas de pesquisar e de atuar no contexto das Comunidades Tradicionais: a construção de identidade. Os processos de subjetivação das mulheres quilombolas tais como os processos de subjetivação das psicólogas nos fazem ver e falar: as mulheres, por meio da negação ou do estranhamento diante das perguntas das pesquisadoras sobre os aparatos culturais típicos de uma tradição ancestral negra, não se reconhecem, necessariamente, como membros de uma comunidade quilombola; alguns se reconhecem tão somente como moradoras de uma comunidade rural como é a comunidade de Macambira, sem por isso deixar de ser uma Comunidade Quilombola. "A identidade étnica é sempre a produção de uma imagem e a transformação do sujeito ao assumir, negar ou negociar essa imagem" (Almeida, 2014, p. 3).

A partir da análise dos processos de subjetivação, pensamos não só no que aquelas mulheres querem transmitir, como também o que aquilo diz do fazer pesquisa: uma abertura à composição de forças presente em um determinado território afetivo. "Um analisador não é apenas um fenômeno cuja função específica é exprimir, manifestar, declarar, evidenciar, denunciar. Ele mesmo contém os elementos para se auto entender, ou seja, para começar o processo de seu próprio esclarecimento" (Baremblitt, 1998, p. 71). De tal modo que todos nós, cartógrafo e cartógrafas, repensamos a pesquisa-intervenção a partir desse conjunto de forças que transversalizava a prática da Psicologia no próprio fazer pesquisa em um contexto de Comunidades Tradicionais.

A noção de território vivo, assinalada na introdução, não diz respeito somente a um espaço geográfico delimitado, mas a uma geografia dos afetos, a partir da qual uma comunidade se afirma e constrói sua identidade. Nesta perspectiva, os processos de subjetivação das mulheres expressam o modo como elas vivem e sonham e como se constroem como mulheres; são mulheres que gritam e pedem passagem para outros modos de ser mulher quilombola. "Em outras palavras, trata-se de analisar e descrever em que jogos de verdade essas mulheres entram para se constituírem como sujeitos de direito étnicos e, ainda, que táticas são utilizadas para escaparem dos processos normalizantes de identificação" (Almeida, 2014, p. 3).

\section{Carta-análise de outros processos de subjetivação}

A Comunidade Quilombola de Macambira vem se transformando junto com o crescimento das cidades vizinhas, Lagoa Nova, Bodó e Santana dos Matos, junto com o próprio movimento do corpo das mulheres, corpo que quer ir além de um nome, que quer construir táticas de escapar dos processos normalizantes de identificação. Pensamos nas cidades crescendo, as cidades empurram-se umas as outras, no processo tecno-ilógico de existir-cidade, que vai construindo outras formas de viver e existir também dentro daquelas comunidades rurais identificadas ou não como quilombolas. "Deus ainda não me deu a graça de ter uma televisão, mas creio que vai chegar a minha vez" (Dona Maimunda, membro da comunidade Macambira).

"A vida é crua. Faminta como o bico dos corvos./ E pode ser tão generosa e mítica: arroio,/ lágrima/ Olho d água, bebida. A vida é líquida" (Hilst, 1998). Abrimos a carta-análise de outros processos de subjetivação com estes versos para contar a história de Djarai, uma das mulheres participantes da pesquisa e que esteve presente durante o encontro, no qual exibimos o curta-metragem Vida Maria (Ramos, 2006). A vida é crua. Djarai por volta dos 11 anos de idade foi trabalhar como doméstica na capital de Natal, no Rio Grande do Norte. Por lá ela sofreu abusos e entrou em um quadro depressivo, inclusive com tentativa de suicídio. Esse sofrimento psíquico a levou a um psiquiatra que a medicou e recomendou que ela voltasse à comunidade. A mãe e a irmã cuidavam dela, já que ela não tinha forças. Aos 15 anos Djarai engravidou e o pai da criança não reconheceu a paternidade, de modo que ela teve que cuidar sozinha do filho. No período em que estava grávida, passou a tomar os medicamentos em dias alternados. Quando a criança nasceu, Djarai decide, por conta própria, parar com a medicação que a deixava sonolenta e incapaz de cuidar da 
criança. A vida é líquida. Djarai volta ao psiquiatra e avisa que parará com a medicação. Djarai, no período da pesquisa, estava há cinco anos sem tomar medicação e estava contente porque tinha voltado a estudar. Mesmo assim, coexistem em torno dela, acolhimento e reconhecimento por parte de outras mulheres e também preconceito e estigma relacionados à loucura, por arte de algumas pessoas da comunidade, como ela relatou, após a sessão de vida Maria.

Mal começamos a exibir o curta, as mulheres já estavam se reconhecendo nas três gerações de mulheres que em criança trabalham; na adolescência trabalham, engravidam e casam; na vida adulta trabalham e cuidam dos filhos, do marido e do pai e; na velhice trabalham e morrem. Participavam desse encontro também uma avó, sua filha e três netas. Comparando-se com as Marias do filme, a mãe-avó narra que sua mãe teve treze filhos, igual à avó de um dos pesquisadores, ela teve sete e sua filha conta que só tem três, pois já se submeteu ao desligamento de trompas.

"Um corpo abriga sons para serem ouvidos" (Preciosa, 2010, p. 26). Ouvimos as mulheres de Macambira, os sons domésticos, o feijão no fogo, a criança chorando no colo. O cabo da enxada entrando no capim seco, som e ritmo de uma sociedade patriarcal, o público/ privado, o masculino/feminino. Adulai é o dono da casa em que realizamos uma Tenda do Conto. Ele toma a iniciativa de começar. Pega sua enxada, objeto afetivo que trouxe para falar de si e inicia sua história: "ela representa minha vida, família, roçado é do que eu vivo, coragem eu tenho é de trabalhar". Mais uma vez os processos de subjetivação segmentados em um gênero dão lugar à participação de outras vozes, além das vozes das mulheres, possibilitando a cartografia de outros sons, outras modulações de sentido. Em seguida, senta a esposa do seu Adulai, dona Maimuna, que tem nos braços uma boneca de pano "as minhas crianças que Deus me deu para mim cuidar, agradeço a Deus". Duas formas de ser-sujeito, o público/privado, o masculino/ feminino. Lánica à frente, mostra um livro de receitas, diz que gostava de ler revistas e livros "hoje num tenho tempo para ler não, só para cozinhar, cuidar da casa, gostaria de fazer um curso de culinária e não gosto mais de ler". Os paradoxais sons do corpo, ora se agitam ora se conformam, "é doida a bioquímica de sons e ritmos que somos feitos" (Preciosa, 2010, p. 26). Diune conta da fase mais feliz de sua vida, aos quatorze anos, quando trabalhava em "casas de família". Salí desabafa as auguras de seu antigo casamento, o marido que bebida, que traía "quando descobri que meu marido me traía larguei dele, minha família me acolheu porque eu não tive culpa" e prossegue "tudo que a gente passa, nossos filhos é nossa alegria, nunca me arrependo”. Outros sons flácidos de dor. "Não tem em que trabalhar aqui, vivo do bolsa-família e quando descasco mandioca".

Abdabi, outro homem que veio ao encontro, conta que sua vida não foi diferente do roçado de Adulai, ele que queria sair dessa vida e não sabia o que era namorar. Foi quando caiu enfermo que conheceu Raci, com a qual é casado há 27 anos. "A gente sem trabalho não é ninguém", diz Abdai com marcas de tempo no rosto cansado. As mulheres também, aparentando mais idade do que têm, muitas vezes executando dupla jornada - quando o marido sozinho não dá conta do roçado - o feijão no fogo, a criança no colo, o cabo da enxada nas mãos. Os sons da falta de reconhecimento, da falta de renda, da falta de espaço público para habilitar-mulher. Outros sons escapam, "me criei agarrada na enxada, minha paixão é limpar mato, nunca brinquei de boneca, eu lutava como menino e com minha enxada" (Dandara). "Desfazer-se desse coágulo é reinvestir no som que jorra forte na garganta, que molda outra linguagem, outro jeito de corpo" (Preciosa, 2010, p. 26).

"O poder que eu quisera é dominar meu medo/ Por este grande dom troco meu verso, meu dedo,/ Meus anéis e colar [...]". (Prado, 2013). Voltemos no tempo, a um dos primeiros encontros com as mulheres da comunidade de Macambira, no qual para iniciar a roda de conversa, recorremos ao uso de desenho, a ideia era desenhar para depois bordar sobre $o$ desenho e apresentar ao final da pesquisa uma manta de bordados. As mulheres resistem. Seus corpos gritam algumas falas de resistência: "eu não sei desenhar porque não estudei”; "não vou conseguir fazer nada"; "nunca costurei na minha vida"; "não sei fazer isso, vai ficar feio". Cartografamos esses processos de subjetivação, agora, analisamos que eles se remetem a linhas duras (Deleuze, \& Guattari, 2012) se desenhando, linhas que organizam um ser-mulher costurado por inúmeras amarras: as amarras da incapacidade, da falta de reconhecimento, do medo. "Tenho medo de me desfigurar [...] tenho medo de não conseguir criar forma alguma, tenho medo de criar uma forma absurda, abominável" (Domingues, 2010, p. 65). 
Nos desdobramentos desse encontro, as psicólogas percebem o quanto aquelas mulheres estão atravessadas por um discurso de desvalorização: por não serem funcionalmente alfabetizadas sentem-se incapazes de partilhar seus conhecimentos. Maimuna e sua filha recusam-se a escolher figuras em revistas e jornais que, do ponto de vista delas, simbolizem os obstáculos, recursos e alternativas que elas identificam na comunidade de Macambira. Elas não aprenderam a ler e a escrever e nisso consiste a sua recusa. Outras duas mulheres olham Maimuna e sua filha, cochicham e riem do medo delas, elas também cheias de medo frente à incapacidade que querem negar. Calam-se com risinhos debochados, sua maneira de manter o medo sob controle.

Os processos de subjetivação das mulheres da comunidade de Macambira também são agenciados por discursos que se materializam no cotidiano, nas relações familiares, afetivas, institucionais e libidinais que produzem uma subjetividade reprimida, insegura, medrosa. Os discursos de algumas delas sobre a forma como se veem e veem as outras apontam para a reprodução de modos de vida cristalizados. Maimuna, por exemplo, demonstra em seu discurso que se sente inferior a outras pessoas que sabem ler e, com isso, limita seu potencial, acreditando que só serve para o trabalho pesado. Um misto de se sentir pequena, em relação às demais, e, ao mesmo tempo, assujeitada, socialmente, a uma dura realidade. Não obstante, algumas linhas se cruzarem, algumas linhas emergirem, linhas de fuga, leves e desterritorializadas. A essa máquina de produção de subjetividade colonial-capitalística (Rolnik, 2018), Guattari e Rolnik (2010) e Deleuze e Guattari (2012) oporiam um agenciamento coletivo do desejo por meio de processos de singularização, uma maneira de "construir modos de sensibilidade, modos de relação com o outro, modos de produção, modos de criatividade que produzam uma subjetividade singular" (Guattari, \& Rolnik, 2010, p. 22).

Salí fala das coisas que teve que aprender sozinha, "as coisas de casa", limpar, cozinhar, cuidar do marido e filhos. Maimuna diz que não sabe ler, mas aprendeu tudo sozinha, pois a mãe faleceu quando ela ainda era criança, de modo que ela teve que cuidar dos irmãos mais novos, cozinhar, limpar a casa e até costurar quando era preciso. "A vida não era fácil e não tinha ninguém para me ensinar, hoje eu cozinho de tudo", lembra dona Maimuna. "A linha do des- tino se desfaz, se abre, se refaz" (Domingues, 2010, p. 63). Podemos ver como a linha do medo se desfaz lentamente na medida em que as mulheres puxam o novelo da memória.

O poder de dominar o medo: cada uma fala agora um pouco sobre sua produção. Os desenhos estampam elementos de suas realidades. Das nove mães que participaram desse encontro, cinco delas desenham suas casas, a coisa mais importante que têm, elas dizem a você: "Quem não tem casa, família, não tem nada". Os desenhos, em sua maioria, são representações da casa, das tarefas domésticas, "do roçado". Processos de singularização, formas de falar de si mais alegres, leves, menos inseguro. Modos de criar uma voz, um discurso mais fortalecido e autoconfiante de si, de seus conhecimentos, valorizar o que se sabe: cuidar da casa, do roçado, criar os filhos, os irmãos, cozinhar, costurar. Mesmo que isso pareça sem valor para elas, afirmar-se de modo a instaurar um gosto de viver e ser do modo que se é. "Quando uma ponta de tristeza se anuncia, ela sorri. Talvez de si, do que sabe não querer e do que quer com força" (Domingues, 2010, p. 62).

É preciso não confundir "minoritário" enquanto devir ou processo, e "minoria" como conjunto ou estado. Os judeus, os ciganos, etc., podem formar minorias nessas e naquelas condições; ainda não o suficiente para fazer delas devir. Reterritorializamo-nos, ou nos deixamos reterritorializar numa minoria como estado; mas desterritorializamo-nos num devir (Deleuze, \& Guattari, 2012, pp. 92-93).

Na comunidade de Macambira observamos tanto momentos de territorialização e reterritorialização identificados como estado ou conjunto, quanto movimentos minoritários de devir-comunidade. É o devir comunitário que arranca uma minoria de sua identidade maior, portanto:

se os próprios judeus têm que devir-judeu, as mulheres que devir-mulher, as crianças que devir-criança, os negros que devir-negros, é porque só uma minoria pode servir de termo medium ativo ao devir, mas em condições tais que ela pare por sua vez de ser um conjunto definível em relação à maioria (Deleuze, \& Guattari, 1997, p. 93). 
Diante destes apontamentos, percebíamos, no início de nossos encontros com as mulheres da comunidade quilombola de Macambira que, no momento em que verbalizávamos o trabalho a ser realizado no dia, algumas mulheres se colocavam num território de insegurança e medo frente à suas capacidades. Percebíamos, nestes momentos, modos segmentados de ser mulher, identificados através das linhas duras da estranheza e da baixa autoestima.

Por outro lado, quando iniciavam as atividades, em contraponto a essas linhas duras de segmentação, iam se delineando as linhas das potencialidades no próprio discurso das mulheres "aprendi tudo que sei sozinha porque minha mãe morreu cedo". Elas falavam através dessas linhas, como aprenderam a cozinhar, cuidar de irmãos e filhos, e outras tantas coisas que sabiam fazer. Apesar de todas as dificuldades provenientes do contexto de suas vidas, especialmente o analfabetismo estrutural e o sexismo, as mulheres conseguiam devir-mulher e devir-comunidade através de suas produções, quando se percebiam capaz de fazer, de falar, de ser - mesmo diante dos ditos de incapacidade construídos socialmente.

Era, portanto, no momento em que as mulheres abandonavam a identidade maior de que ser mulher naquela comunidade era ser incapaz e servir apenas ao trabalho pesado, que elas conseguiam devir-mulher saindo do território duro desta identidade, desterritorializando-se na leveza de sentir-se capaz de falar de si, de reconhece suas potencialidades, de fazer aquilo que elas achavam que não eram capazes de fazer.

\section{Carta-considerações finas com reticências...}

"Menina, eu queria te compor/ Em verso,/ Cantar os desconcertantes/ Mistérios/ Que brincam em ti,/ Mas teus contornos me/ Escapolem./ Menina, meu poema primeiro,/ Cuida de mim" (Evaristo, 2010, p. 22). Pesamos na carta-amizade e na importância da amizade como exercício político. Pois percebemos, naquele momento, o quanto os laços de amizade encontravam-se enfraquecidos na comunidade de Macambira. As psicólogas desejam cantar a elas versos desconcertantes, versos de resistência. Cuidem-se umas as outras, mulheres, é isso que elas querem dizer. O penúltimo encontro com as mulheres da comunidade de Macambira aconteceu na casa de Maimuna, devido à impossibilidade de ser reali- zado na Casa de Farinha, por conta da desavença das mulheres com Maimuna. Diune, que sempre estava presente nos encontros, quando soube que o encontro seria na casa de Maimuna, decide voltar para casa.

As psicólogas aceitam os pedidos de desculpas de Diune "só eu sei o que vou ter que escutar depois", referindo-se ao que a comunidade vai falar por ela estar na casa de Maimuna. "Nessa casa só quem fala comigo é o marido dela”, diz desconfortável Diune. Percebemos nesses processos de subjetivação que marcam o discurso de Diune o enfraquecimento dos laços políticos de amizade na comunidade, que se reflete no empobrecimento do alcance de conquistas na esfera dos direitos políticos e sociais, inclusive.

"Aqui todo mundo é intrigado", Diune comenta. Ela diz às vezes em que se deparou com os olhares de julgamento, os cochichos, a indiferença, os movimentos de ridicularização da fala de umas em relação às outras. O último encontro também aconteceu na casa de Maimuna, mas, antes disso, as psicólogas visitam as mulheres, como de costume, para avisar do local e horário do encontro. Visitam a casa de Diune e mostram a importância da presença dela - e também da relevância de romper com esses laços de inimizade. Elas percebem sua resistência e novamente seu olhar de decepção. Ela diz que vai pensar. É um começo. Para surpresa do grupo de pesquisa, quando o encontro vai começar, Diune aparece, envergonhada. Você observa o quanto aquele movimento de Diune foi importante para quebrar a barreira do preconceito e do orgulho. A possibilidade de experimentar outros modos de ser-vizinhança.

A relação de amizade como espaço privilegiado de ação e discurso - compreendidos como experiência essencialmente políticas, além de permitir um vínculo de escuta acolhida em que se compartilha e significa a vida, pode possibilitar um movimento de desvio, de rupturas na economia dominante, estabelecendo um espaço de experimentação política através da troca de experiências, de informações e conhecimentos, configurando um espaço repleto de trocas de aprendizagens e de experimentação imprevisto (Gomes, \& Silva-Júnior, 2010, p. 77).

Neste último encontro, as psicólogas-pesquisadoras sentem a alegria dos bons encontros. Percebem como há espaço de voz e escuta. Sentem enfraquecer 
as vibrações dos risos debochados. Uma brecha aos encontros, uma alegria ativa de avizinhar-se. Sentem que há entre as mulheres uma aposta na sororidade, política de amizade e solidariedade feminina, por isso sentem vibrar com o vento os afetos dos antepassados negros daquelas mulheres, delas e de todos nós cartógrafo e cartógrafas. É o fim do encontro e o começo da alteridade do campo territorial-afetivo. Então, concluímos que cartografar é mergulhar nos afetos que permeiam os contextos e as relações que pretendemos conhecer, permitindo ao pesquisador também se inserir na pesquisa e comprometer-se com o objeto pesquisado, para fazer um traçado singular do que se propõe estudar.

Neste estudo, falamos da importância da análise de implicação e da atenção às virtualidades que se delineiam no modo de fazer pesquisa-intervenção. Apostamos na invenção e afirmamos: é preciso que estejamos atentos e atentas aos encontros, às virtualidades que se estalam, nos agenciam e que são oriundas de desestalizações que, no processo de trabalho, acometem tanto o pesquisador, quanto o seu objeto de estudo, seu campo. Assim, falamos das mulheres, das linhas duras e organizadas que produzem modos de ser cristalizados, bem como das linhas de fuga que se transversalizam a partir dos encontros. Falamos de vida e morte, de alegria, de potência de criação de outros modos de vida na Comunidade Remanescente de Quilombolas de Macambira, de outros modos de ser mulher, de ser vizinho e de avizinhar-se. Falamos também de outros modos de pesquisar, cartograficamente, transversalmente, afetivamente.

\section{Referências}

Almeida, M. A. (2014). A experiência de mulheres quilombolas: Raça e gênero na criação de corpos étnicos. Anais do Congresso Regional de História da Anpuh-Rio: Saberes e práticas científicas, Rio de Janeiro, RJ, Brasil, 16. Recuperado de http://www.encontro2014.rj.anpuh.org/resources/anais/28/1402090314_ARQUIVO_MarileaAnpuh2014-Versaofinal-1.pdf

Alvarez, J., \& Passos, E. (2010). Cartografar é habitar um território existencial. In: E. Passos, V. Kastrup, \& L. Escóssia (Orgs.), Pistas do método da cartografia: Pesquisa-intervenção e produção de subjetividade (pp. 131-149). Porto Alegre, RS: Sulinas.

Arruti, J. M. A. (1997). A emergência dos "remanescentes": Notas para o diálogo entre indígenas e quilombolas. Mana, 3(2), 7-38. https://doi.org/10.1590/S0104-93131997000200001

Arruti, J. M. A. (2006). Mocambo: Antropologia e história no processo de formação quilombola. Bauru, SP: Edusc.

Baptista, L. A. (1999). A cidade dos sábios. São Paulo SP: Summus.

Baremblitt, G. (1988). Compêndio de análise institucional e outras correntes (4a ed.). Rio de Janeiro, RJ: Record.

Barros, R. B. (2013). Grupo: A afirmação de um simulacro (3a ed.). Porto Alegre, RS: Sulina.

Conselho Federal de Psicologia. (2017). Relações raciais: Referências técnicas para atuação de psicólogas/os. Brasília, DF: o autor.

Cordeiro, P. S. (2016). Cartas para uma escrita a perigo: Ensaios, arranjos e ficções (Tese de doutorado). Universidade Federal Fluminense, Rio de Janeiro, SP.

Decreto $\mathrm{N}^{\circ} 3.912$, de 10 de setembro de 2001. Regulamenta as disposições relativas ao processo administrativo para identificação dos remanescentes das comunidades dos quilombos e para o reconhecimento, a delimitação, a demarcação, a titulação e o registro imobiliário das terras por eles ocupadas. Diário Oficial da União. 11 set.

Deleuze, G. (2006). A ilha deserta: E outros textos. São Paulo, SP: Iluminuras.

Deleuze, G., \& Guattari, F. (2015). Kafka por uma literatura menor (C. V. Silva, Trad.). Belo Horizonte, MG: Autêntica.

Deleuze, G., \& Guattari, F. (2012). Mil platôs: Capitalismo e esquizofrenia (Vol. 4, S. Rolnik, Trad., 2a ed.). Rio de Janeiro, RJ: 34.

Domingues, L. (2010). À flor da pele: Subjetividade, clínica e cinema no contemporâneo. Porto Alegre, RS: Sulina.

Educação Permanente em Saúde em Movimento - EPS em Movimento.. (2014). Diário cartográfico. Recuperado de http://eps.otics.org/material/entrada-apresentacao/arquivos-em-pdf/diario-cartografico/view 
Evaristo, C. (2008). Poemas da recordação e outros movimentos. Belo Horizonte, MG: Nandaya.

Evaristo. C. (2010). Poemas de recordação e outros movimentos. Rido de Janeiro, RJ: Malê.

Ferraz, M. C. F. (2002). Nove variações sobre temas nietzschianos. Rio de Janeiro, RJ: Relume Dumará.

Gomes, L. G. N., \& Silva Júnior, N. S. (2010). Amizade e experimentação política: Solidariedade e resistência entre amigos nas classes populares. Arquivos Brasileiros de Psicologia, 62(1), 72-83.

Guattari, F. (1981). Revolução molecular: Pulsações políticas do desejo. (S. Rolnik, Trad.). São Paulo, SP: Brasiliense.

Guattari, F., \& Rolnik, S. (2010). Micropolítica: Cartografias do desejo (10a ed.). Petrópolis, RJ: Vozes.

Hilst, H. (1998). Da poesia. São Paulo, SP: Companhia das Letras.

Kastrup, V. (2008). O método da cartografia e os quatro níveis da pesquisa intervenção. In: L. R. Castro, \& V. L. Besset (Orgs.), Pesquisa intervenção na infância e juventude (pp. 465-489). Rio de Janeiro, RJ: Trarepa.

Marques, C. E. (2018). A questão quilombola no Brasil contemporâneo: Do governo FHC aos governos petistas. In: F. Coelho, \& R. S. Camacho (Orgs.), O campo no Brasil contemporâneo: Do governo FHC aos governos petistas: Protagonistas da/na luta pela terra/territorio e das políticas públicas (Vol. 2, pp. 133-148). Curitiba, PR: CRV.

Mello, A. (1999). Mulheres em construção: Casas, sonhos, subjetividade. São Paulo, SP: EDUC.

Mello, M. M. (2009). Mocambo: Antropologia e história no processo de formação quilombola. Mana, 15(2), 585588. https://doi.org/10.1590/S0104-93132009000200010

Negri, T. (2001). Exílio, seguido de valor e afeto (R. Cordeiro, Trad.). São Paulo, SP: Iluminuras.

Negri, T., \& Guattari, F. (2017). As verdades nômades: Por novos espaços de liberdade (M. A. Marinho, \& J. Viel, Trad.). São Paulo, SP: Autonomia Literária.

Pereira, E. M. M. (2007). Comunidade de Macambira: De "negros da Macambira" à associação quilombola (Relatório antropológico). Natal, RN: Universidade Federal do Rio Grande do Norte.

Prado, A. (2013). O coração disparado. Rio de Janeiro, RJ: Record.

Preciosa, R. (2010). Rumores discretos da subjetividade: Sujeito e escritura em processo. Porto Alegre, RS: Sulina.

Ramos, M. (2006).Vida Maria. PortaCultura. Recuperado de http://portacurtas.org.br/filme/?name=vida_maria

Ribeiro, D. (2018). Quem tem medo do feminismo negro? São Paulo, SP: Companhia das Letras.

Rolnik, S. (2018). Esferas da Insurreição. São Paulo, SP: n-1 edições.

Rolnik, S. (2000). Toxicômanos de identidade. In: D. Lins, P. Bourdieu, S. Rolnik, \& L. Wacquant (Orgs.), Cultura e subjetividade: Saberes nômades (2a ed., pp. 19-24). Campinas, SP: Papirus.

Santos, A. O., Schucman, L. V., \& Martins, H. V. (2012). Breve histórico do pensamento psicológico brasileiro sobre relações étnico-raciais. Psicologia: Ciência e Profissão, 32(Esp.), 166-175. https://doi.org/10.1590/S141498932012000500012

Santos, M. M. (2016). O direito quilombola nas encruzilhadas jurídicas: Marinha do Brasil x Quilombo Rio dos Macacos. In: J. C. S. Rocha (Org.), Direito, sustentabilidade ambiental e grupos vulneráveis (pp. 57-77). Salvador, BA: Universidade Federal da Bahia.

Santos, M., \& Silveira, M. L. (2010). O Brasil: Território e sociedade no início do século XXI (13a ed.). Rio de Janeiro, RJ: Record.

Sawaia, B. B. (2008). O sofrimento ético-político como categoria de análise da dialética exclusão/inclusão. In: B. B. Sawaia (Org.), As artimanhas da exclusão: Análise psicossocial e ética da desigualdade social (10a ed., pp. 97-118). Petrópolis, RJ: Vozes.

Schmitt, A., Turatti, M. C. M., \& Carvalho, M. C. P. (2002). Atualização do conceito de quilombo: Identidade e território nas definições teóricas. Ambiente \& Sociedade, (10), 129-136. https://doi.org/10.1590/S1414-753X2002000100008

Schwarcz, L. M., \& Starling, H. M. (2015). Brasil: Uma biografia. São Paulo, SP: Companhia das Letras.

Silva, T. T. (2009) Documentos de identidade: Uma introdução às teorias do currículo (3a ed.). Belo Horizonte, MG: Autêntica. 
Yamamoto, O. H. (2012). 50 anos de profissão: Responsabilidade social ou projeto ético-político? Psicologia: Ciência e Profissão, 32(n. esp), 6-17. https://doi.org/10.1590/S1414-98932012000500002

\section{Antonio Vladimir Félix-Silva}

Professor do Programa de Pós-graduação em Psicologia da Universidade Federal do Piauí (UFPI), Parnaíba PI. Brasil.

E-mail: wladyfelix@hotmail.com

iD https://orcid.org/0000-0003-3084-379X

\section{Gabriela Pinheiro Soares}

Psicóloga e pós-graduanda pela Fundação Gregório Baremblitt, Uberaba/Instituto Félix Guattari, Belo Horizonte - MG. Brasil.

E-mail: gabypsoares@hotmail.com

(iD https://orcid.org/0000-0001-8697-8445

\section{Ana Caroline Santos}

Graduada em Psicologia pela Universidade Potiguar (UnP), Natal - RN. Brasil. Pós-graduada em Psicodiagnóstico pelo Centro Universitário Christus, Fortaleza - CE. Brasil.

E-mail: anacarolineds@gmail.com

(iD) https://orcid.org/0000-0003-4597-7854

\section{Lara Mendes Braga Rigoti}

Mestranda em Psicologia pela Universidade Federal do Rio Grande do Norte, Natal - RN, Brasil. Graduada em Psicologia pela Universidade Potiguar (UnP), Natal - RN. Brasil.

E-mail: laramendesb@gmail.com

(D) https://orcid.org/0000-0002-3249-6990

\section{Maria Valquiria Nogueira Nascimento}

Professora Adjunta I da Universidade Federal de Campina Grande (UFCG), Campina Grande - PB. Brasil. Doutora em Psicologia pela Universidade Federal do Rio Grande do Norte, Natal - RN, Brasil.

E-mail: valquiriarn@yahoo.com.br

(D) https://orcid.org/0000-0002-7547-592X

Endereço para Correspondência:

Avenida São Sebastião, 3950. Apartamento 8.

Bairro Frei Higino.

Parnaíba-PI

CEP: 64207-005

Recebido 11/04/2019

Aceito 06/05/2019

Received 04/11/2019

Approved 05/06/2019

Recibido 11/04/2019

Aceptado 06/05/2019 
Como citar: Félix-Silva, A. V., Soares, G. P., Santos, A.C., Rigoti, L. M. B., \& Nascimento, M. V. N. (2019). A Psicologia no contexto das comunidades tradicionais: Da emergência étnica à perspectiva ético-estético-política. Psicologia: Ciência e Profissão, 39(n.spe)., 130-146. https://doi.org/10.1590/1982-3703003222599

How to cite: Félix-Silva, A. V., Soares, G. P., Santos, A.C., Rigoti, L. M. B., \& Nascimento, M. V. N. (2019). Psychology in the context of traditional communities: From the ethnic emergence to the ethical-esthetic-political perspective. Psicologia: Ciência e Profissão, 39(n.spe)., 130-146. https://doi.org/10.1590/1982-3703003222599

Cómo citar: Félix-Silva, A. V., Soares, G. P., Santos, A.C., Rigoti, L. M. B., \& Nascimento, M. V. N. (2019). A La Psicología en el contexto de las comunidades tradicionales: De la emergencia étnica a la perspectiva éticoestético-política. Psicologia: Ciência e Profissão, 39(n.spe)., 130-146. https://doi.org/10.1590/1982-3703003222599 